\title{
EFFECT OF SEEPAGE-INDUCED NON-HYDROSTATIC PRESSURE DISTRIBUTION ON BEDLOAD TRANSPORT AND BED MORPHODYNAMICS
}

\author{
Simona Francalanci ${ }^{1}$, Gary Parker ${ }^{2}$ and Luca Solari ${ }^{3}$
}

\begin{abstract}
The Shields number, or Shields stress, provides a classical nondimensionalization expressing the relative mobility of a sediment particle on the bed of a river. It is not commonly recognized, however, that the Shields number implicitly contains the assumption of a hydrostatic pressure distribution in the water immersing the particles. While such an assumption is accurate for a wide range of rectilinear, quasi-steady and quasi-uniform flows, it fails in a wider range flows, i.e. the flow in the vicinity of an obstacle such as a bridge pier. If the concept underlying the Shields number is correct, however, the Shields number should be generalizable to non-hydrostatic pressure distributions. Here such a generalization is attempted for the case of a non-hydrostatic pressure distribution produced by a vertical seepage flow. Measurements of the scour or fill produced by this seepage in a region of an erodible bed suggest that an appropriately generalized Shields number does indeed capture the effect of a non-hydrostatic pressure distribution on sediment mobility.
\end{abstract}

CE Database subject headings: Non-Hydrostatic pressure; Sediment transport; seepage; dimensionless shear stress.

\section{Introduction}

Fluvial sediment mobility has been traditionally expressed in terms of the dimensionless Shields number $\tau_{*}$, defined as follows; where $\tau_{b}=$ boundary shear stress, $g=$ gravitational acceleration, $D=$ characteristic grain size of sediment at the bed surface, $\rho=$ density of water and $\rho_{\mathrm{s}}$ denotes sediment density,

$$
\tau_{*}=\frac{\tau_{b}}{\left(\rho_{s}-\rho\right) g D}
$$

The Shields number specifically scales the ratio of the impelling drag force of the water acting on a grain at the bed surface (numerator) to the Coulomb force that resists motion, which can be taken to be proportional to the immersed weight of the grain (denominator). This can be seen more clearly by rewriting (1) in the form

$$
\tau_{*}=\frac{4}{3} \frac{\tau_{\mathrm{b}} \frac{1}{2} \pi\left(\frac{\mathrm{D}}{2}\right)^{2}}{\left(\rho_{\mathrm{s}}-\rho\right) \mathrm{g} \frac{4}{3} \pi\left(\frac{\mathrm{D}}{2}\right)^{3}}
$$

The threshold of motion has been defined in terms of a critical Shields number $\tau_{\mathrm{c}}^{*}$ (Shields, 1936), and appropriately defined dimensionless measures of the 
magnitude of sediment transport have been taken to be functions of the Shields number (e.g. the version of the bedload transport relation of Meyer-Peter and Müller, 1948, specified by Chien, 1954). In more recent years the concept of the Shields number has been extended to encompass a vectorial boundary shear stress vector that may act in an arbitrary direction within the plane of the bed (e.g. Parker et al., 2003; Francalanci and Solari, 2005; Francalanci, 2006).

It does not seem to be generally recognized, however, that by its very definition the Shields number assumes the pressure distribution of the water in which sediment grains are immersed to be hydrostatic. Consider, for example, a spherical grain of diameter $D$. The origin of the term $\left(\rho_{s}-\rho\right)$ in (1) and (2) is the assumption that the downward gravitational force $F_{g}$ corresponding to the weight of an immersed particle, given as

$$
F_{g}=\rho_{s} g \frac{4}{3} \pi\left(\frac{D}{2}\right)^{3}
$$

is partially counterbalanced by the upward Archimedian buoyant pressure force $F_{p}$ corresponding to the weight of the displaced fluid, given as

$$
\mathrm{F}_{\mathrm{p}}=\rho g \frac{4}{3} \pi\left(\frac{\mathrm{D}}{2}\right)^{3}
$$

so that the effective gravitational force $F_{g}^{\prime}$ of the particle is given as

$$
F_{g}^{\prime}=F_{g}-F_{p}=\left(\rho_{s}-\rho\right) g \frac{4}{3} \pi\left(\frac{D}{2}\right)^{3}
$$

The above term specifically appears in the denominator of (2).

The form of the buoyant pressure force given by (4) is obtained from the assumption of a hydrostatic pressure distribution, i.e. one such that pressure $p$ satisfies the relation

$$
\frac{\partial \mathrm{p}}{\partial \mathrm{x}_{\mathrm{i}}}=-\rho \mathrm{g} \delta_{\mathrm{i} 3}=-\rho \mathrm{g}(0,0,1)
$$

where $x_{i}$ denotes the position vector in index notation, $x_{3}=z$ denotes the upward vertical coordinate and $\delta_{\mathrm{ij}}$ denotes the Kronecker delta. The vectorial pressure force $F_{p i}$ acting on an immersed grain is given as

$$
F_{p i}=-\left.\iint p\right|_{\text {surface }} n_{o i} d S
$$

where the pressure is evaluated at the surface of the particle, $\mathrm{n}_{\mathrm{oi}}$ is an outward normal unit vector to the surface, and dS is an element of surface area. Reducing (7) with the divergence theorem and evaluating the result under the assumption of hydrostatic pressure according to (6), it is found that

$$
\mathrm{F}_{\mathrm{pi}}=-\iiint \frac{\partial \mathrm{p}}{\partial \mathrm{x}_{\mathrm{i}}} \mathrm{dV}=\left[0,0, \rho \mathrm{g} \frac{4}{3} \pi\left(\frac{\mathrm{D}}{2}\right)^{3}\right]
$$

i.e. the vectorial generalization of (4). 
The assumption of hydrostatic pressure is an accurate one for the case of nearly steady, relatively uniform rectilinear flow. In the case of flow around an obstacle such as a bridge pier, however, non-hydrostatic pressure forces can be significant. If the Shields number does indeed represent an appropriate nondimensional ratio characterizing sediment transport, the concept should somehow generalize to non-hydrostatic pressure distributions.

The net force acting on a bed particle due to a non-hydrostatic pressure distribution can in principle act in any direction. Here, however, for simplicity the problem is restricted to pressure variation solely in the vertical, so that

$$
\frac{\partial \mathrm{p}}{\partial \mathrm{x}_{1}}=\frac{\partial \mathrm{p}}{\partial \mathrm{x}_{2}}=0
$$

A dimensionless number $\mathrm{Nh}$ characterizing deviation from hydrostatic conditions can then be defined as

$$
\mathbf{N h}=-\frac{1}{\rho g} \frac{\partial p}{\partial x_{3}}
$$

An extension of (8) using (10) leads to the following relation for the pressure force on an immersed bed particle;

$$
\mathrm{F}_{\mathrm{pi}}=\left[0,0, \rho g \frac{4}{3} \pi\left(\frac{\mathrm{D}}{2}\right)^{3} \mathrm{Nh}\right]
$$

where $\mathbf{N h}$ is evaluated at the sediment bed. Thus a vertical pressure gradient that is stronger than hydrostatic in the vertical $(\partial \mathrm{p} / \partial \mathrm{z}<-\rho \mathrm{g}$ and $\mathbf{N h}>1)$ in the vicinity of a grain on the bed leads to an enhanced buoyant force on the grain, and a vertical pressure gradient that is weaker than hydrostatic $(\partial \mathrm{p} / \partial \mathrm{z}>-\rho \mathrm{g}$ and $\mathrm{Nh}<1$ ) in the vertical leads to a reduced buoyant force on the grain. The former case ought to make a grain effectively lighter and thus more mobile, and the latter case should make the same grain effectively heavier and thus less mobile, as illustrated in Figure 1.

The appropriate generalization of the Shields number that correctly characterizes the pressure force for this case is

$$
\tau_{*}=\frac{\tau_{\mathrm{b}}}{\left(\rho_{\mathrm{s}}-\rho \mathrm{Nh}\right) \mathrm{gD}}
$$

As expected, a value of $\mathbf{N h}$ that is somewhat greater than 1 , for example, reduces the denominator, and thus increase $\tau_{*}$ and hence the mobility of a grain on the bed. If the concept of the Shields number itself is correct, a correlation between dimensionless sediment transport rate and Shields number that works for a hydrostatic pressure distribution should also work for the non-hydrostatic pressure distribution hypothesized here, with the simple generalization of the Shields number from (1) to (12). This paper is devoted to the testing of this hypothesis.

Vertical seepage as a means of generating a non-hydrostatic pressure distribution 
Cheng and Chiew (1999) considered the case of upward seepage flow in a granular, erodible bed under an open channel flow. They found that such a seepage flow reduces the critical shear velocity for the onset of motion of the bed sediment at the surface. Their method was adapted to the present work to create a non-hydrostatic pressure distribution within the pore water of the sediment bed.

Here a seepage, or groundwater flow is allowed only in the vertical direction. The piezometric head $h_{p}$ is given as

$$
h_{p}=\frac{p}{\rho g}+z
$$

The vertical velocity of seepage $v_{s}$ is related to $h_{p}$ according to D'Arcy's law:

$$
v_{s}=-K \frac{d h_{p}}{d z}=-K\left(1+\frac{1}{\rho g} \frac{d p}{d z}\right)
$$

where $\mathrm{K}$ denotes the hydraulic conductivity of the granular bed. Between (10), (12) and (14) it is readily seen that

$$
\begin{aligned}
& \text { Nh }=-\frac{1}{\rho g} \frac{d p}{d z}=1+\frac{v_{s}}{K} \\
& \tau_{*}=\frac{\tau_{b}}{\left[\rho_{s}-\rho\left(1+\frac{v_{s}}{K}\right)\right] g D}
\end{aligned}
$$

An upward seepage thus causes a non-hydrostatic pressure distribution with $\mathrm{Nh}$ $>1$, and thus enhanced particle mobility according to (16), and a downward seepage has the opposite effect. These tendencies are summarized in Figure 1. As noted below, the cases studied here include both upward and downward seepage.

\section{Experimental setup and protocol}

Experiments were carried out in a glass-sided sediment-recirculating, water-feed flume that was $15 \mathrm{~m}$ long, $0.61 \mathrm{~m}$ wide and $0.4 \mathrm{~m}$ deep. The incoming water discharge was controlled by a valve and monitored with an electromagnetic flow meter. The bed of the flume was covered with sediment. Nearly all the water overflowed from a collecting tank at the downstream end of the flume and exited the system. The sediment settled to the bottom of the collecting tank, and was recirculated with a jet-pump system to the upstream end of the flume with a small discharge of water as a slurry, where it was re-introduced. A sketch of the flume is provided in Figure $2 a$.

Upward or downward groundwater flow was introduced in a reach between $9 \mathrm{~m}$ and $10.1 \mathrm{~m}$ downstream of the upstream end of the flume. The seepage flow passed through a seepage box buried underneath the flume bed. The seepage box had a length of $1.1 \mathrm{~m}$, a width $0.61 \mathrm{~m}$ and a height of $0.06 \mathrm{~m}$. A perforated sheet over the top of the box regulated the seepage flow, which was 
verified to be nearly uniform over the length of the reach and width of the flume. A fine filter was inserted above the perforated sheet in order to separate the sand layer from the water inside the box. In the case of upward seepage, water was delivered by a second jet pump into a seepage box through a pipeline. The groundwater flow discharge to the seepage box was regulated by a valve and measured by an electromagnetic flow meter. In the case of downward seepage the water was extracted from the seepage box by a suction pump. A sketch of the configuration for the seepage box is given in Figure $2 \mathrm{~b}$.

A relatively uniform sediment was chosen for the experiments in order to minimize sorting effects. The characteristic size was chosen such that the effect of bedforms was not too large. In addition, trial experiments with a variety of sediment sizes showed that uniform groundwater flow could not be maintained when the sediment was too fine, and that the seepage discharge could not be controlled accurately when the sediment was too coarse. These trial experiments allowed the selection of a sediment with a value of hydraulic conductivity $\mathrm{K}$ that was appropriate for the experiments.

The sediment selected for the experiments was subject to some initial sorting, because the finest material in the mix was gradually washed out of the collection box. After some time, however, the sediment in the flume equilibrated to a median size $D_{50}$ and geometric mean size $D_{g}$ both near $0.84 \mathrm{~mm}$, a size $D_{35}$ near $0.69 \mathrm{~mm}$, a size $D_{90}$ near $1.48 \mathrm{~mm}$ and a geometric standard deviation $\sigma_{\mathrm{g}}$ near 1.62. Hydraulic conductivity $\mathrm{K}$ was measured with a D'Arcy tube and found to be near $0.0025 \mathrm{~m} / \mathrm{s}$.

Velocity measurements were performed using a micro-propeller with a diameter of $14 \mathrm{~mm}$. A point gage was used to measure water surface elevations and the elevation of the bed. Five bed elevation points were measured for each transverse cross-section; the average of these values was assumed as the cross-sectional mean value of the bottom elevation for the purpose of characterizing long profiles. Measurements of sediment transport in the flume were obtained by diverting slurry from the sediment recirculation pipe and measuring the sediment mass collected as a function of time.

The experimental protocol was designed around Table 1 . The table encompasses inflow discharges $\mathrm{Q}_{w}$ ranging from 12 to 20.6 liters/sec, upward seepage discharges $\mathrm{Q}_{\text {seepage }}$ ranging from $20-140$ liters/min and downward seepage discharges $\mathrm{Q}_{\text {seepage }}$ ranging from 30 - 90 liters/min, for a total of 27 experimental conditions, 18 of which pertained to upward seepage and 9 of which pertained to downward seepage. In principle, each experimental condition corresponded to a set of three experiments, one with no seepage, one with data acquired after 10 minutes of seepage (short-term experiment) and one with data acquired after 2 or 4 hours of seepage (the longer time span corresponding to lower seepage rates). Run 2-2, for example, corresponds to the second-highest 
seepage rate for Run Code 2 in Table 1, for which $\mathrm{Q}_{w}=16$ liters/sec and $\mathrm{Q}_{\text {seepage }}$ $=40$ liters $/ \mathrm{min}$.

The first experiment in each set of three was conducted with the specified value of inflow discharge $\mathrm{Q}_{w}$ but in the absence of seepage. Each such experiment was continued until mobile-bed equilibrium was obtained; the results provided baseline data on sediment transport and flow resistance. In some cases a run was repeated in order to test for consistency. As a consequence, results for 33 experiments without seepage are reported here.

For the second experiment of each set of three, the flow was restarted, but this time with the introduction of seepage over the $1.1 \mathrm{~m}$ reach specified in Figure $2 a$. The bed elevation was allowed to evolve due to the effect of the seepage flow, and the flow was stopped after 10 minutes to measure the bed profile. These experiments are referred to as "short-term experiments." For the third experiment of each set, the flow was restarted and then continued for a total of 2 hours (higher seepage rate) or 4 hours (lower seepage rate), after which data were acquired. Both durations include the 10 minutes of the short-term experiment. These experiments are referred to as "long-term experiments." Longterm experiments were not performed, however, for cases with a seepage discharge $\mathrm{Q}_{\text {seepage }}$ of 140 liters/min. In several cases short-term and long-term experiments were repeated, in order to confirm the experimental data. In the case of repeated runs, the values for the data reported here were typically obtained by averaging the data from the repeat experiments. In a very small number of cases of long-term experiments, the duration differed between the repeat experiments ( 2 hours versus 4 hours); in such cases the data are reported separately.

\section{Mobile-bed equilibrium in the absence of seepage}

A total of 33 experiments were first performed so as to obtain mobile-bed equilibrium conditions in the absence of seepage. These experiments were performed with flow discharges $\mathrm{Q}_{w}$ ranging from 12.0 to 20.6 liters/sec (Table 1). Each experiment was continued for a minimum of 12 hours in order to ensure that mobile-bed equilibrium was attained. In all cases sediment was observed to move exclusively as bedload transport. The bedforms that covered the bed at mobile-bed equilibrium can be seen in Figure 3.

In the absence of sediment loss from the collection box at the downstream end of the flume, the total mass of sediment is conserved in a sedimentrecirculating flume. In the flume used for the experiments the downstream elevation of the bed was held constant by an overflow wall. The combination of these two conditions requires that the bed slope at mobile-bed equilibrium be constant for a given mass of sediment in the flume, and that this same bed slope must increase linearly with increasing mass of sediment in the flume. While the total amount of sediment in the flume was varied somewhat from run to run, the 
equilibrium bed slope $S$ varied within a relatively narrow range for the 33 experiments without seepage, with 79 percent of the experiments showing a value of $S$ within $\pm 10 \%$ of a value of 0.00384 .

The results of the measurements at mobile-bed equilibrium allowed the characterization of hydraulic resistance and bedload transport. Part of the drag force of the flow in the flume is expended against the inerodible vertical sidewalls of the flume, and thus does not contribute to sediment transport. The part of the drag force expended against the erodible bed of the flume can be further decomposed into form drag associated with the bedforms and skin friction; only the latter is effective in moving sediment in bedload transport. The total boundary shear stress on the bed $\tau_{b}$ is here characterized in terms of the corresponding total bed shear velocity $u_{*}$, where

$$
\mathrm{u}_{*}=\sqrt{\frac{\tau_{\mathrm{b}}}{\rho}}
$$

The total bed shear velocity was estimated from the following relation appropriate for steady, uniform flow;

$$
\mathrm{u}_{*}=\sqrt{\mathrm{gRS}}
$$

where $\mathrm{R}=$ the hydraulic radius of the bed region (as opposed to the sidewall region), here estimated from the relation

$$
R= \begin{cases}\frac{B}{4} & \text { for } H>B / 2 \\ \frac{1}{B}\left[H^{2}+H(B-2 H)\right] & \text { for } H<B / 2\end{cases}
$$

of Vanoni (1957); in the above relation $B=$ channel width and $\mathrm{H}=$ flow depth. The shear velocity $u_{*}^{\prime}$ of the bed region associated with skin friction only was estimated using the relation for C' due to White et al. (1980), i.e.

$$
\mathrm{u}_{*}^{\prime}=\frac{\mathrm{U}_{\text {measured }}}{\mathrm{C}^{\prime}}=\frac{\mathrm{U}_{\text {measured }}}{5.65 \log _{10}\left(10.6 \frac{\mathrm{H}}{\mathrm{D}_{35}}\right)}
$$

where $U_{\text {measured }}$ denotes the cross-sectionally averaged flow velocity as determined from measurements with a propeller meter. The Shields number associated with total bed friction $\tau_{*}$ and the corresponding Shields number $\tau_{*}^{\prime}$ associated with skin friction only were then computed as

$$
\tau_{*}=\frac{\rho u_{*}^{2}}{\left(\rho_{\mathrm{s}}-\rho\right) g \mathrm{D}_{35}} \quad, \quad \tau_{*}^{\prime}=\frac{\rho u_{*}^{\prime 2}}{\left(\rho_{\mathrm{s}}-\rho\right) g \mathrm{D}_{35}}
$$

The use of sediment size $D_{35}$ in the above equations is in accordance with the method of White et al. (1980). A plot of $\tau_{*}^{\prime}$ versus $\tau_{*}$ is given in Figure 4; the Shields number due to form drag $\tau_{*}^{\prime \prime}$ indicated in the figure is given as

$$
\tau_{*}^{\prime \prime}=\tau_{*}-\tau_{*}^{\prime}
$$


An estimate of the critical Shields number $\tau_{* \mathrm{cr}}$ for the onset of sediment motion is shown in Figure 4; this value was estimated to be equal to 0.0388 in accordance with the criteria of Ackers and White (1973).

It was found that the bedload transport rates observed in the 33 experiments pertaining to mobile-bed equilibrium in the absence of seepage could be accurately predicted using the sediment transport relation of Ackers and White (1973). This notwithstanding, any test of the Shields number as a characterization of sediment mobility is best performed in terms of a sediment transport relation based on the Shields number. The data were used to develop such a relation. The volume bedload transport rate per unit width $q_{b}$ was made dimensionless in terms of the Einstein number $\mathrm{q}_{*}$, where

$$
q_{*}=\frac{q_{b}}{\sqrt{\frac{\rho_{\mathrm{s}}-\rho}{\rho} \mathrm{gD}_{35}} D_{35}}
$$

As illustrated in Figure 5, the data were fitted to a sediment transport relation of the form

$$
\mathrm{q}_{*}=0.0201 \cdot\left(\frac{\tau_{*}^{\prime}}{\tau_{* \mathrm{rr}}}\right)^{2.5266}
$$

where the critical Shields number $\tau_{* \text { cr }}$ takes the above-quoted value of 0.0388 .

\section{Experiments on the effect of seepage on bed morphodynamics}

Figure 6 illustrates the effect of upward seepage on bed morphology. The conditions are for those of Run 1-2, i.e. $\mathrm{Q}_{w}=20.6$ liters $/ \mathrm{sec}$ and $\mathrm{Q}_{\text {seepage }}=40$ liters/min. (A compendium of all measured bed profiles can be found in Francalanci, 2006). Figure $6 a$ shows a view of the bed in the vicinity of the zone of seepage; the mean slope of the profile has been removed for clarity. The long profiles of the initial bed (i.e. bed at mobile-bed equilibrium in the absence of seepage), at the end of short-term experiment (10 minutes) and at the end of the long-term experiment (4 hours) are shown. It is evident that the channel has scoured in the zone of seepage. Figure $6 \mathrm{~b}$ shows the initial and final long profiles of a much longer flume reach for the long-term experiment; the profiles have not been detrended to remove the mean slope. Also shown in Figure $6 \mathrm{~b}$ is the water surface profile at the end of the long-term experiment. It is clear from Figure $6 \mathrm{~b}$ that scour in the seepage zone has been accompanied by some bed aggradation in the zone upstream. This pattern is dictated by the constraint of sediment recirculation; since the total mass of sediment is conserved, the mass of sediment eroded from the seepage zone must be deposited elsewhere.

Scour depth $\Delta \eta_{s}$ in the seepage zone was determined relative to the elevation of the bed at mobile-bed equilibrium before the onset of seepage. Two measures were computed, i.e. the mean scour depth $\overline{\Delta \eta}_{\mathrm{s}}$ and the maximum 
scour depth $\Delta \eta_{\mathrm{sm}}$. Both were made dimensionless into the respective forms $\bar{\varepsilon}_{\mathrm{s}}$ and $\varepsilon_{\text {sm }}$ using the mean flow depth $\mathrm{H}$ that prevailed at mobile-bed equilibrium before the onset of seepage;

$$
\bar{\varepsilon}_{\mathrm{s}}=\frac{\overline{\Delta \eta_{\mathrm{s}}}}{\mathrm{H}}, \quad \varepsilon_{\mathrm{sm}}=\frac{\Delta \eta_{\mathrm{sm}}}{\mathrm{H}}
$$

Figures $7 \mathrm{a}$ and $7 \mathrm{~b}$ respectively show the dimensionless maximum scour depth $\varepsilon_{s m}$ and mean scour depth $\bar{\varepsilon}_{\mathrm{s}}$ plotted against the discharge ratio $\mathrm{Q}_{\text {seepage }} / \mathrm{Q}_{w}$. The data are further stratified according to the Shields number $\tau_{*}$ prevailing at mobile-bed equilibrium before the onset of seepage, computed in accordance with (17) and (21a). Data are shown in Figures $7 \mathrm{a}$ and $7 \mathrm{~b}$ for both the short-term experiments (open symbols) and long-term experiments (closed symbols). The overall tendency is for both measures of scour depth $\varepsilon_{\mathrm{sm}}$ and $\bar{\varepsilon}_{\mathrm{s}}$ to increase with increasing discharge ratio $\mathrm{Q}_{\text {seepage }} / \mathrm{Q}_{w}$. The long-term experiments show greater scour depths than the short-term experiments, indicating that 10 minutes is not in general sufficient to reach mobile-bed equilibrium in the presence of seepage. The data show only a weak tendency to stratify according to Shields number, with in general more scour at higher Shields numbers.

Figure 8 illustrates the effect of downward seepage. The conditions are those of Run 5.2, for which $\mathrm{Q}_{w}$ was equal to 16 liters/sec and $\mathrm{Q}_{\text {seepage }}$ was equal to 60 liters/min. Figure 8 a shows bed profiles for the initial condition (mobile-bed equilibrium in the absence of seepage), at the end of the short-term experiment (10 minutes) and at the end of the long-term experiment (4 hours), all in the vicinity of the seepage zone. In correspondence to Figure $6 a$, the mean slope has been removed for clarity. The figure illustrates the effect of downward seepage in inducing deposition. Figure $8 \mathrm{~b}$ shows the initial and final long profiles of a much longer flume reach for the long-term experiment; the profiles have not been detrended to remove the mean slope. Also shown in Figure $8 \mathrm{~b}$ is the water surface profile at the end of the long-term experiment. In correspondence to Figure $6 \mathrm{~b}$, the deposition in the seepage zone has been accompanied by bed degradation upstream of the seepage zone.

The thickness of deposition $\Delta \eta_{d}$ in the seepage zone was measured analogously to the scour depth in the case of the experiments with upward seepage; i.e. bed elevation in the seepage zone was measured relative to the bed elevation prevailing at mobile-bed equilibrium before the onset of seepage. These measurements yielded values for mean and maximum thicknesses of deposition, i.e. $\overline{\Delta \eta_{\mathrm{d}}}$ and $\Delta \eta_{\mathrm{dm}}$, respectively. These were made dimensionless using the mean flow depth $\mathrm{H}$ prevailing in the absence of seepage, so that

$$
\bar{\varepsilon}_{\mathrm{d}}=\frac{\overline{\Delta \eta_{\mathrm{d}}}}{\mathrm{H}}, \quad \varepsilon_{\mathrm{dm}}=\frac{\Delta \eta_{\mathrm{dm}}}{\mathrm{H}}
$$

Figures $9 \mathrm{a}$ and $9 \mathrm{~b}$ show respectively the dimensionless maximum thickness of deposition $\varepsilon_{\mathrm{dm}}$ and mean thickness of deposition $\bar{\varepsilon}_{\mathrm{d}}$ plotted against the discharge 
ratio $\mathrm{Q}_{\text {seepage }} / \mathrm{Q}_{w}$. The data are further stratified according to the Shields number $\tau_{*}$ in the same way as for Figures $7 \mathrm{a}$ and $7 \mathrm{~b}$. Data are shown in Figures $9 \mathrm{a}$ and $9 \mathrm{~b}$ for both the short-term experiments (open symbols) and long-term experiments (closed symbols). Again the overall tendency is for both measures of depositional thickness $\varepsilon_{\mathrm{dm}}$ and $\bar{\varepsilon}_{\mathrm{d}}$ to increase with increasing discharge ratio $\mathrm{Q}_{\text {seepage }} / \mathrm{Q}_{\mathrm{w}}$, although the trend is very weak in the case of the short-term maximum deposit thickness. The long-term experiments generally show greater depositional thicknesses than the short-term experiments, again indicating that 10 minutes is not in general sufficient to reach mobile-bed equilibrium in the presence of seepage.

\section{How seepage affects bed morphodynamics}

The experimental results reported above clearly indicate that upward seepage induces scour and downward seepage induces deposition. Before pursuing a numerical model of the morphodynamics of erodible-bed openchannel flow in the presence of seepage, it is of value to provide an overview as to how flow-sediment interaction in the presence of seepage gives rise to scour or deposition. Three effects play important roles; a) the effect of seepage on the bed shear stress $\left.\tau_{b}, b\right)$ the direct effect of seepage on the Shields number itself, and c) the effect of seepage on the critical Shields number for the onset of motion.

Cheng and Chiew (1998a,b) have shown that over a wide range of conditions upward seepage reduces the bed shear stress $\tau_{b}$ in the zone of seepage. The same model implies that downward seepage increases the bed shear stress. The effect can be illustrated in terms of the St. Venant equations for conservation of water and flow momentum in the presence of seepage, which take the forms

$$
\begin{aligned}
& \frac{\partial \mathrm{H}}{\partial \mathrm{t}}+\frac{\partial \mathrm{UH}}{\partial \mathrm{x}}=\mathrm{v}_{\mathrm{s}} \\
& \frac{\partial \mathrm{UH}}{\partial \mathrm{t}}+\frac{\partial \mathrm{U}^{2} \mathrm{H}}{\partial \mathrm{x}}=-\mathrm{gH} \frac{\partial \mathrm{H}}{\partial \mathrm{x}}+\mathrm{gHS}-\frac{\tau_{\mathrm{b}}}{\rho}
\end{aligned}
$$

where $\mathrm{x}=$ streamwise distance, $\mathrm{t}=$ time and $\mathrm{U}=$ depth-averaged flow velocity. Note that for simplicity the channel has been assumed wide enough to neglect sidewall effects in (27a) and (27b). Reducing the above-two equations for steady flow, it is found that

$$
\tau_{\mathrm{b}}=\rho g \mathrm{HS}-\rho g \mathrm{H} \frac{\mathrm{dH}}{\mathrm{dx}}\left(1-\frac{\mathrm{U}^{2}}{\mathrm{gH}}\right)-2 \rho U v_{\mathrm{s}}
$$

The actual relation used by Cheng and Chiew (1998a) for bed shear stress is slightly different from (28a) in that it allows for the velocity profile to be modified from the uniform flow by means of the momentum correction factor.

The first term on the right-hand side of (28) gives the standard depth-slope product rule for bed shear stress in the absence of backwater and seepage 
effects (and also the absence of sidewall effects). The third term on the righthand side of (28) embodies the direct effect of seepage on bed shear stress; it invariably acts to decrease shear stress in the presence of upward seepage $\left(v_{s}>\right.$ 0 ) and increase it in the presence of downward seepage $\left(v_{s}<0\right)$. The second term in (28) embodies the effect of backwater generated by seepage. All the experiments reported here were sufficiently into the range of subcritical flows so that the term $1-U^{2} /(g H)$ was always positive in the seepage zone. In addition, $\mathrm{dH} / \mathrm{dx}$ was negative in the seepage zone for upward seepage, and positive in the seepage zone for downward seepage. The second term in (28) thus always had a sign opposite to that of the third term in (28), but the magnitude was always less, and typically about one-half. Thus the net effect of seepage was always to reduce the bed shear stress relative to the value that would prevail in the absence of seepage.

This effect is illustrated in Figure 10. Let $\tau_{\text {bs }}$ denote the bed shear stress in the presence of seepage, $\tau_{\text {ba }}$ denote the value in the absence of seepage and $U_{\text {upstream }}$ denote the flow velocity well upstream of the seepage region (and thus upstream of seepage-induced backwater). Figure 10 shows a plot of the ratio $\tau_{\text {bs }} / \tau_{\text {ba }}$ versus the ratio $v_{s} / U_{\text {upstream. }}$. The closed points refer to the experiments reported here for the case of upward seepage. The values of $\tau_{\text {bs }}$ were computed from (28) evaluated in the middle of the seepage zone. The calculations are based on numerically predicted profiles for water surface elevation in the presence of seepage (but before scour has occurred) rather than experimental profiles, because the latter contained considerable scatter. Having said this, the numerical profiles were adjusted so as to provide good fits of the experimental profiles. The results clearly indicate a suppression of bed shear stress in the presence of upward seepage. Also shown in Figure 10 are estimates obtained by Cheng and Chiew (1998a) for the case of upward seepage, which also illustrate the same trend.

The effect of upward seepage, i.e. to reduce bed shear stress at the middle of the seepage zone relative to the value that would prevail in the absence of seepage, suggests that this effect alone would lead to deposition rather than scour in the zone of upward seepage. This conclusion is, however, not correct because it does not account for the entire profile of bed shear stress created by both the seepage and the backwater created by it. The profiles of flow depth $\mathrm{H}$ and bed shear stress $\tau_{b}$ prevailing immediately after the commencement of upward seepage over a short zone (but before the bed has had a chance to evolve morphodynamically in response) are schematized in Figure 11. Upward seepage creates a backwater effect upstream, such that $\mathrm{H}$ increases and bed shear stress $\tau_{b}$ decreases downstream toward the upstream end of the seepage zone. The effect of upward seepage on subcritical flow is such that the depth decreases, and the flow velocity and bed shear stress increase over the seepage zone. As a result the bed shear stress in the middle of the seepage zone is below the value prevailing in the absence of seepage, but above the bed shear stress in the backwater zone immediately upstream of the 
seepage zone. This pattern causes deposition in the backwater zone upstream of the zone of upward seepage, but scour in the seepage zone itself. The pattern is reversed in the case of downward seepage.

Two further effects of seepage act to change the mobility of the sediment itself. One of these is the direct effect of the seepage-induced non-hydrostatic pressure gradient on the denominator of the Shields number, as embodied in the forms (12) and (16). The other of these is associated with a change in the critical Shields number $\tau_{* \text { *r }}$ in the presence of seepage, as elucidated by Cheng and Chiew (1999).

D'Arcy's law (14) can be rewritten in terms of the hydraulic gradient i as follows;

$$
\mathrm{v}_{\mathrm{s}}=\mathrm{Ki} \quad, \quad \mathrm{i}=-\frac{\mathrm{dh}}{\mathrm{dz}}=-\left(1+\frac{1}{\rho \mathrm{g}} \frac{\mathrm{dp}}{\mathrm{dz}}\right)
$$

The critical upward seepage rate $i_{c}$ at which the induced pressure force just balances the macroscopic weight of a granular bed, i.e. the bed becomes quick, is given by Cheng and Chiew (1999) as

$$
\mathrm{i}_{\mathrm{c}}=\left(\frac{\rho_{\mathrm{s}}}{\rho}-1\right)\left(1-\lambda_{\mathrm{p}}\right)
$$

where $\lambda_{p}$ denotes bed porosity. As long as the hydraulic conductivity $K$ remains independent of the seepage rate (a condition verified for the present experiments based on information in Cheng and Chiew, 1999), (29) and (30) can be used to define a critical seepage rate $v_{s c}$ for a quick bed such that

$$
\mathrm{v}_{\mathrm{sc}}=\mathrm{K}\left(\frac{\rho_{\mathrm{s}}}{\rho}-1\right)\left(1-\lambda_{\mathrm{p}}\right)
$$

Now let $\tau_{* \mathrm{cr}, \mathrm{S}}$ denote the critical Shields number for the onset of sediment motion in the presence of seepage and $\tau_{* \mathrm{cr}, \mathrm{a}}$ denote the corresponding value in the absence of seepage. Cheng and Chiew (1999) find the following relation;

$$
\frac{\tau_{* \mathrm{cr}, \mathrm{s}}}{\tau_{* \mathrm{cr}, \mathrm{a}}}=1-\frac{\mathrm{v}_{\mathrm{s}}}{\mathrm{v}_{\mathrm{sc}}}
$$

The above relation indicates that upward seepage decreases the threshold Shields number for the onset of sediment motion, as demonstrated by the experiments of Cheng and Chiew (1999). Conversely, downward seepage should increase the threshold Shields number for the onset of motion.

\section{Numerical model of bed morphodynamics in the presence of seepage}

The effect of seepage, and by extension non-hydrostatic pressure variation in the vertical direction near the bed, can be modeled numerically using 
a 1D formulation. Where $\eta$ denotes bed elevation, the Exner equation of sediment conservation takes the form

$$
\left(1-\lambda_{p}\right) \frac{\partial \eta}{\partial t}=-\frac{\partial q_{b}}{\partial x}
$$

In a sediment-recirculating flume, the boundary condition on (33) is cyclic; i.e. where $x=0$ denotes the upstream end of the flume and $x=L$ denotes the downstream end,

$$
\left.\mathrm{q}_{\mathrm{b}}\right|_{\mathrm{x}=\mathrm{L}}=\left.\mathrm{q}_{\mathrm{b}}\right|_{\mathrm{x}=0}
$$

In principle the bed shear stress in the numerical model should be computed using a method that removes the effects of the vertical sidewalls (Vanoni, 1957). Here this was not implemented for simplicity. In the experiments without seepage, the width-depth ratio $\mathrm{B} / \mathrm{H}$ at mobile-bed equilibrium ranged from 10.0 to 15.7 , values that are large enough to at least partially justify this approximation. The classical quasi-steady approximation was used in conjunction with the standard shallow water equations in calculating the flow, so that (27a) and (27b) take the form

$$
\begin{aligned}
& \frac{d U H}{d x}=v_{s} \\
& \frac{d U^{2} H}{d x}=-g H \frac{d H}{d x}+g H S-\frac{\tau_{b}}{\rho}
\end{aligned}
$$

Bed shear stress $\tau_{\mathrm{b}}$ was evaluated from a logarithmic formulation;

$$
\tau_{b}=\rho C_{f} U^{2} \quad, \quad C_{f}^{-1 / 2}=2.5 \ln \left(11 \frac{\mathrm{H}}{k_{s}}\right)
$$

where $\mathrm{C}_{\mathrm{f}}$ denotes a bed friction coefficient and $\mathrm{k}_{\mathrm{s}}$ denotes a roughness height. The roughness height $k_{s}$ was compute as

$$
\mathrm{k}_{\mathrm{s}}=\mathrm{n}_{\mathrm{k}} \mathrm{D}_{50}
$$

The dimensionless parameter $n_{k}$ was found to vary from flow to flow due to the effect of bedforms. Here the value of $n_{k}$ was calibrated using experimental data for mobile-bed equilibrium flows in the absence of seepage, and the same value of $n_{k}$ was applied to a corresponding experiment with seepage.

All the flows considered here were subcritical in the Froude sense. In the case of mobile-bed equilibrium without seepage, for example, the Froude number varied from 0.71 to 0.82 . As a result, (35a) and (35b) could be solved by integrating upstream from the downstream end of the flume. In principle the downstream boundary condition should consist of a set water surface elevation. The wall at the downstream end of the flume, however, imposed a set bed elevation instead. A quasi-equilibrium calculation using the backwater profile evaluated at the previous time step allowed an estimate of the downstream depth that a) led to the satisfaction of sediment conservation and b) specified a downstream boundary condition for a backwater calculation of the flow field which takes into account the constraint of inerodibility of the bed near the overflow wall at the downstream end of the flume. 
An abrupt change from a vanishing seepage velocity to a finite seepage velocity at $x=9 \mathrm{~m}$, and a similar abrupt change to vanishing seepage velocity at $\mathrm{x}=10.1 \mathrm{~m}$ tended to result in numerical instability in the model. Spurious oscillations were suppressed in two ways. Firstly, an artificial diffusion term was added to (33), modifying it to

$$
\left(1-\lambda_{p}\right) \frac{\partial \eta}{\partial t}=-\frac{\partial q_{b}}{\partial x}+D_{f} \frac{\partial^{2} \eta}{\partial x^{2}}
$$

Values of $D_{f}$ in the range $10^{-5} \sim 10^{-4} \mathrm{~m}^{2} / \mathrm{s}$ were found to be adequate for this purpose. Secondly, the abrupt change in seepage velocity at the upstream and downstream ends of the seepage reach was replaced with very short zones over which seepage velocity varied in smoothly according to a sinusoidal function. In addition, the seepage rate was slowly increased at the beginning of each numerical experiment until it attained its asymptotic value.

The effect of seepage was brought into the formulation in each of the three ways outlined in the previous section. The formulation of (35a) and (35b) allows computation of the effect of seepage on the bed shear stress $\tau_{\mathrm{b}}$. In implementing the formulation of (24) for bedload transport, the Shields number due to skin friction $\tau_{*}^{\prime}$ was computed as

$$
\tau_{*}^{\prime}=\frac{\rho u_{*}^{\prime 2}}{\left[\rho_{\mathrm{s}}-\rho\left(1+\frac{\mathrm{v}_{\mathrm{s}}}{\mathrm{K}}\right)\right] \mathrm{gD}_{35}}
$$

using the generalization embodied in (12) and (16), and $\tau_{* \text { *r }}$ was computed according to (32). Equation (39) specifically brings the effect of a non-hydrostatic pressure distribution into the calculation of bedload transport.

The equations were solved using an explicit finite-difference scheme, employing the predictor-corrector scheme and upwinding in the computation of the spatial derivative of bedload transport in (38). Results of the numerical calculations are presented in the next section.

\section{Comparison of experimental and numerical results}

Comparisons of the results of the numerical model against those of the experiments for the case of upward seepage are given in Figures 12a and 12b. Both figures pertain to Run 1-3. Figure 12a shows the initial measured bed profile (i.e. the profile at mobile-bed equilibrium in the absence of seepage), and the measured and computed final bed profiles at the end of the short-term experiment. Figure $12 \mathrm{~b}$ shows the corresponding profiles for the long-term experiment. Only a reach in the vicinity of the zone of seepage is shown in the figure; the effect of the mean bed slope has been removed from both figures for clarity. Figures $12 \mathrm{a}$ and $12 \mathrm{~b}$ show that the numerical model reasonably captures the observed pattern of seepage-induced scour both in the short and long terms. 
The numerically calculated profiles are smoother than the observed profiles because the numerical model does not capture the individual bedforms.

A similar comparison is shown in Figures $13 \mathrm{a}$ and $13 \mathrm{~b}$ for the case of downward seepage. Both figures pertain to Run 4-1, with the former figure characterizing the short term and the latter characterizing the long term. The numerical model somewhat underpredicts the pattern of deposition induced by downward seepage, but the overall patterns of the experiments are clearly reflected in the model results.

It can be seen from Figures 12 and 13 that the numerical model predicts that upward seepage increases the bed slope in the seepage zone as compared to mobile-bed equilibrium in the absence of seepage, and downward seepage similarly decreases the bed slope. Predictions in this regard are summarized in Figure 14 for 9 runs with upward seepage and 2 runs with downward seepage. The results are for long-term calculations, with the bed slope computed as an average over the seepage zone.

Figures $15 \mathrm{a}$ and $15 \mathrm{~b}$ allow comparison between predicted and observed mean scour depths/deposition thicknesses. Similarly to Figure 14, values are shown for 9 experiments with upward seepage and 2 experiments with downward seepage. Scour is represented in terms of the dimensionless parameter defined in (25a); the negative scour depths in Figures 15a and 15b indicate deposition, the magnitude of the dimensionless thickness of which is given by (26a). Figure 15a pertains to short-term experiments, and Figure 15b pertains to long-term experiments. Dimensionless scour is plotted against the discharge ratio $\mathrm{Q}_{\text {seepage }} / \mathrm{Q}_{w}$.

Although the numerical model somewhat underpredicts the magnitude of both scour and deposition, the trends are very similar, and most of the predicted values fall within the scatter of the observed values. The results of Figures $15 \mathrm{a}$ and $15 \mathrm{~b}$ allow for the following tentative conclusion. Incorporation of the effect of seepage so as to a) correct the prediction of the bed shear stress, b) correct the critical Shields number and c) correct the expression for the Shields number itself so as to account for the non-hydrostatic vertical pressure gradient induced by seepage allows the numerical model to capture with reasonable accuracy the effect of seepage on bed morphodynamics. It can similarly be tentatively concluded that the bedload transport equation (24) determined in the absence of seepage effects can be applied to the case where a seepage-induced nonhydrostatic vertical pressure gradient prevails by means of the generalizations (32) and (39).

\section{Discussion}

As noted above, the numerical model incorporates three modifications due to seepage: a) modification of the bed shear stress $\tau_{b}$, and modification of the 
parameters b) $\tau_{*}^{\prime}$ and c) $\tau_{* \text { cr }}$ used in the computation of bedload transport. The effects of the non-hydrostatic pressure distribution induced by seepage are embodied in b) and c). It is of value to study the morphodynamic evolution that would result when factor a) is retained but factors b) and c) associated with the non-hydrostatic pressure distribution are neglected. The predictions of the model for bed evolution in this case are shown in Figure 16. The profiles shown therein pertain to the results of 6 short-term runs with upward seepage only. The predicted patterns of scour and fill are very different from those obtained by including non-hydrostatic effects, as can be seen by comparing with Figures $6 \mathrm{a}$ and $6 \mathrm{~b}$. The implication is that the inclusion of non-hydrostatic effects is essential in order to obtain the generally good performance of the numerical model indicated by Figures $15 \mathrm{a}$ and $15 \mathrm{~b}$.

The generally positive performance of the numerical model as evidenced by Figures $15 \mathrm{a}$ and $15 \mathrm{~b}$ suggests the possibility of useful extensions to the computation of sediment transport in general non-hydrostatic flow fields. Examples of such flow fields are those which would prevail near an obstacle such as a bridge pier, abutment or sharp river bend. Such flow fields should give rise to a near-bed gradient in the mean pressure field $\partial \mathrm{p} / \partial \mathrm{x}_{\mathrm{i}}$ (averaged over turbulence) that deviates from hydrostatic in all three directions, rather than just the vertical direction considered here. The component of this pressure gradient vector which acts tangential to the bed generates a force that must be added to the impelling force associated with the tangential shear stress of the bed in computing sediment transport. The component of this pressure gradient vector acting normal to the bed exerts a force either pushing the particle against the bed (and so reducing mobility) or buoying it away from the bed (and so increasing mobility). A generalized formulation of sediment transport would naturally include all these effects, and so allow for an accurate computation of sediment transport in zones of highly non-hydrostatic pressure variation.

Turbulence closure models such as k- $\varepsilon$ and k- $\omega$ (Rodi, 1980), as well as large-eddy simulation models predict not only the entire flow field but also the pressure field, including any deviation of the pressure (averaged over turbulence) from hydrostatic. Such models thus predict information that is as yet unused in the computation of sediment transport and scour near obstacles. The work presented here provides a first example as to how the predicted pressure field can be incorporated into calculations of sediment transport, and thus scour and fill near obstacles.

The real challenge in the computation of sediment transport and bed morphodynamics in the vicinity of obstacles as bridge piers is the accurate prediction of scour patterns. The flow field and bed near such obstacles is characterized not only by highly non-hydrostatic pressure fields, but also highly 2D patterns of boundary shear stress, as well as a bed that may have a substantial 2D bed slope. Parker et al. (2003), Francalanci and Solari (2005) and Francalanci (2006) have developed tools to compute vectorial bedload transport 
associated with vectorial bed shear stress and vectorial bed slope of substantial magnitude. The potential addition of the effect of non-hydrostatic pressure fields to the sediment transport formulation opens a new avenue toward the numerical evaluation of local scour via the linkage of higher-order fluid mechanical models of turbulent flow with higher-order formulations for sediment transport.

One caveat deserves mention in regard to the effect of seepage on sediment transport. The pressure force associated with vertical seepage given by (11) is accurate within a granular bed, but is subject to some inaccuracy at the boundary between the granular bed and the flow above. The accuracy of the model could be improved by means of a generalization to e.g. the groundwater flow model of Brinkman (1947).

\section{Conclusions}

The dimensionless Shields number, or Shields stress, implicitly includes the assumption of a hydrostatic pressure distribution in its denominator. The assumption is reasonable for quasi-steady, quasi-uniform rectilinear sediment transport, but breaks down in the case of sediment transport near an obstacle such as a bridge pier. A generalization of the Shields number is proposed for the case of a near-bed non-hydrostatic pressure gradient in the vertical direction. Such a gradient can be produced by upward or downward groundwater flow.

Experiments were performed in a water-feed, sediment-recirculating flume with a length of $15 \mathrm{~m}$ in order to study the effect of seepage on sediment transport. Experiments were performed in the absence of seepage to determine appropriate relations for flow resistance and sediment transport. Seepage was then induced over a $1.1 \mathrm{~m}$ reach toward the downstream end of a flume with a length of $15 \mathrm{~m}$. Upward seepage caused scour in the zone of seepage; downward seepage produced deposition. These patterns were predicted reasonably well by a numerical model of morphodynamic evolution that incorporated the following seepage-induced effects; a) modification of the bed shear stress, b) modification of the critical Shields number for the onset of motion and c) modification of the Shields number itself to account for the non-hydrostatic pressure distribution.

The research suggests a new avenue toward the accurate prediction of sediment transport and scour patterns around flow obstacles such as bridge piers, where a) the bed shear stress is strongly $2 \mathrm{D}$; b) the bed slope is strongly 2D and may be of substantial magnitude and c) the pressure distribution is strongly non-hydrostatic.

\section{Notations}

$\mathrm{B}=$ channel width

$\mathrm{C}_{f}=$ bed friction coefficient

$\mathrm{D}=$ characteristic grain size of sediment at the bed surface 


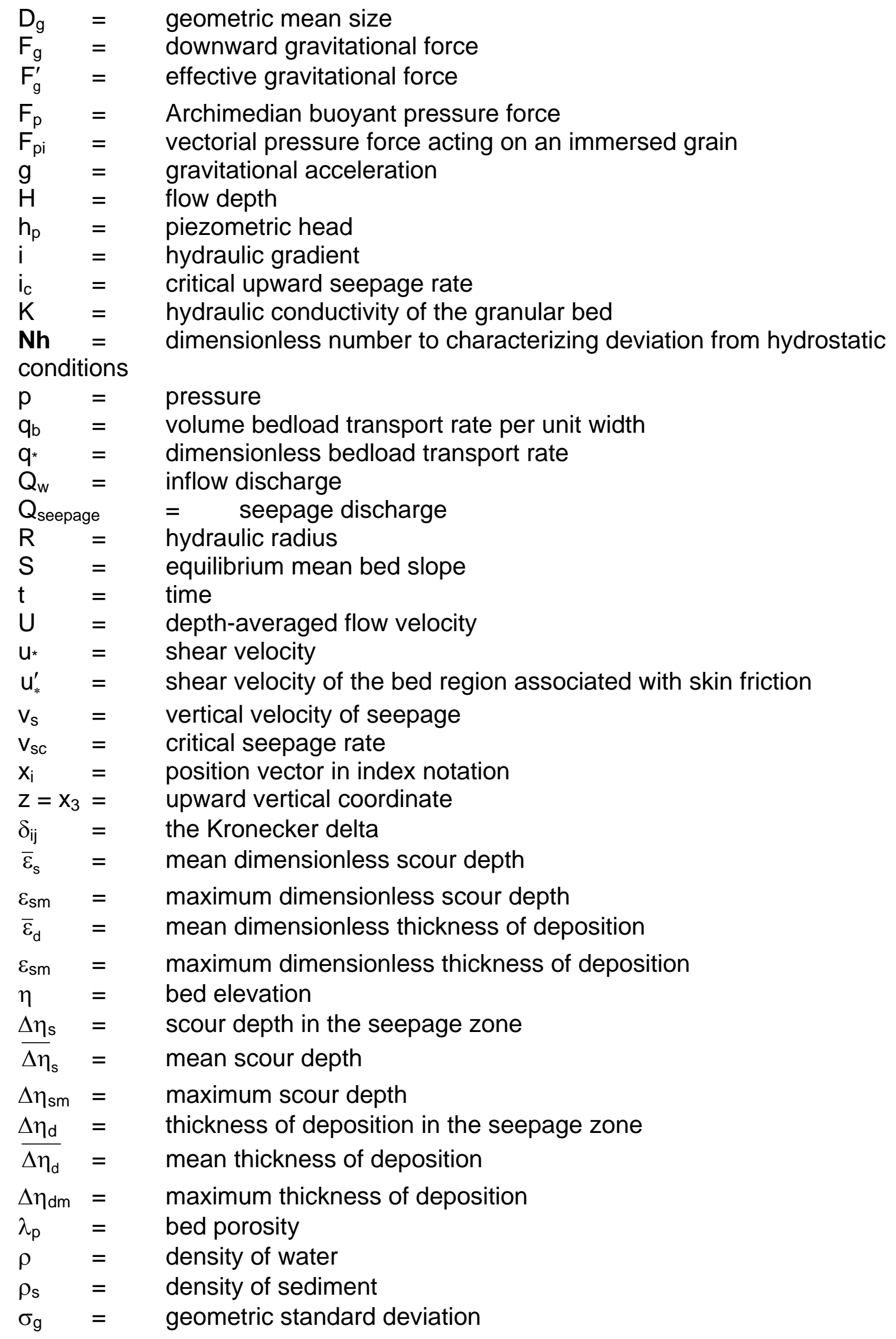


$\tau_{*} \quad=\quad$ dimensionless Shields number

$\tau_{c}^{*}, \tau_{* c r, a}=$ critical dimensionless Shields number

$\tau_{* \mathrm{cr}, \mathrm{s}}=$ critical Shields number for the onset of sediment motion in the

presence of seepage

$\tau_{*}{ }^{\prime}=$ dimensionless Shields number associated with skin friction

$\tau_{*}{ }^{\prime}=$ dimensionless Shields number associated with form drag

$\tau_{\mathrm{b}}=$ boundary shear stress

$\tau_{\text {ba }}=$ bed shear stress in the absence of seepage

$\tau_{\text {bs }}=$ bed shear stress in the presence of seepage

\section{Acknowledgements}

Prof. Enio Paris is greatly acknowledged for his support in the present research and for his precious comments and suggestions.

The experiments reported here were performed at St. Anthony Falls Laboratory, University of Minnesota. These experiments were supported in part by the visitor program of the National Center for Earth-surface Dynamics (NCED), a Science and Technology Center of the United States National Science Foundation. This paper represents a contribution to the effort of NCED in the area of channel dynamics. Preliminary results of the present work were published in the Conference Proceedings of RCEM 2005 and River Flow 2006.

\section{References}

Ackers, P. and White, W. (1973). "Sediment transport in open channel: Ackers and White update". Journal of Hydraulic Engineering, 99(HY4), 1-37.

Brinkman, H. C. (1947). "A calculation of the viscous force exerted by a flowing fluid on a dense swarm of particles". Appl. Sci. Res., 1, 27-34.

Chien, N. (1954). "Meyer-Peter formula for bed-load transport and Einstein bedload function." M.R.D. Sediment Series No. 7, University of CaliforniaBerkeley, and The Missouri River Division, U.S. Army Corps of Engineers, Berkeley, California, $32 \mathrm{pp}$.

Francalanci, S. (2006). "Sediment transport processes and local scale effects on river morphodynamics". Ph.D. thesis, University of Padova, Italy, $144 \mathrm{p}$.

Chen, X. and Chiew, Y. M. (2004) "Velocity distribution of turbulent open-channel flow with bed suction". Journal of Hydraulic Engineering., 140(2), 140-148.

Cheng, N. S. and Chiew, Y. M. (1998a) "Turbulent open-channel flow with upward seepage". Journal of Hydraulic Research, 36(3), 415-431.

Cheng, N. S. and Chiew, Y. M. (1998b) "Modified logarithmic law for velocity distribution subjected to upward seepage". Journal of Hydraulic Engineering., 124(12), 1235-1241.

Cheng, N. S. and Chiew, Y. M. (1999) "Incipient sediment motion with seepage". Journal of Hydraulic Research, 37(5), 665-681.

Chiew, Y. M. and Parker G. (1994) "Incipient sediment motion on non-horizontal slopes". Journal of Hydraulic Research, 32(5), 649-660. 
Francalanci, S. and Solari, L. (2005). "A particle tracking technique to study gravitational effects on bedload transport". Proc. of $3^{\text {rd }}$ RCEM Conference, Volume 1, pp. XXX, Urbana, IL.

Meyer-Peter, E., and Müller, R. (1948). "Formulas for bed-load transport." Proc., 2nd Meeting, IAHR, Stockholm, Sweden, 39-64.

Parker, G., Seminara, G. and Solari, L. (2003). "Bedload at low Shields stress on arbitrarily sloping beds: alternative entrainment formulation." Water Resources Research, 39(7), 1183, doi:10.1029/2001WR001253, 11 p.

Rodi, W. "Turbulence models and their application in hydraulics - A state of the art review". Institut fur Hydromechanik, University of Kalsurhe, 1980, 104 p.

Shields, A. (1936) Application of similitude mechanics and research on turbulence to bed load movement. Mitteilungender Preussischer Versuchsanstalt fur Wasserbau und Schiffbau 26 in German.

Vanoni, V. A., and Brooks, N. H. (1957) "Laboratory studies of the roughness and suspended load of streams", Rep. E68, Sedimentation Lab., California Institute of Technology, Pasadena, Calif.

White, W., Paris, E. and Bettess, R. (1980). "The frictional characteristics of alluvial streams: a new approach." Proceedings, Inst. of Civil Engineers, 69(2), 737-750. 


\begin{tabular}{ccc}
\hline Run Code & $\begin{array}{c}Q_{w} \\
{[l / s]}\end{array}$ & $\begin{array}{c}Q_{\text {seepage }} \\
{[l / m]}\end{array}$ \\
\hline 1 & 20.6 & $20,40,60,80,100,140$ \\
2 & 16 & $20,40,60,80,100,140$ \\
3 & 12 & $20,40,60,80,100,140$ \\
4 & 20.6 & $30,60,90$ \\
5 & 16 & $30,60,90$ \\
6 & 12 & $30,60,90$ \\
\hline
\end{tabular}

Table 1: Hydraulic conditions for the experiments; Run Codes $1 \div 3$ pertain to runs with upward groundwater flow, and Run Codes $4 \div 6$ pertain to runs with downward groundwater flow.
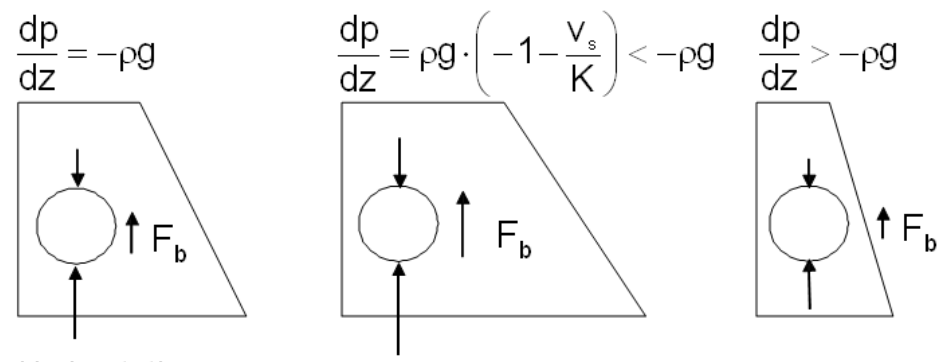

Hydrostatic pressure: Archimedian increased Non-hydr. pres.: buoyant force buoyant force

decreased buoyant force

Figure 1: Vertical pressure gradient $d p / d z$ near the bed and buoyant force $F_{b}$ acting on a bed particle. 


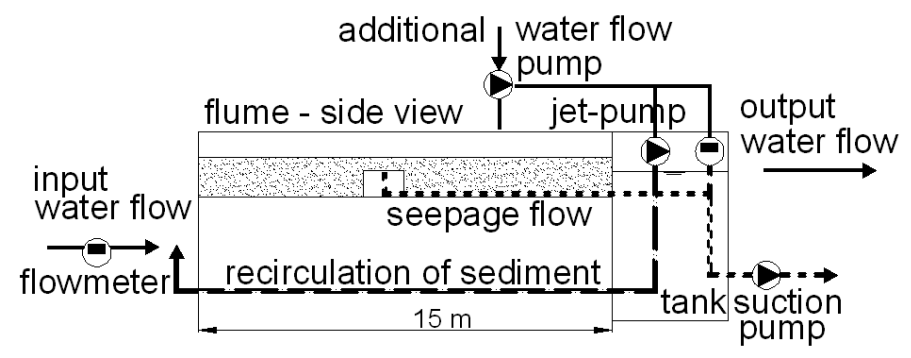

(a) Sketch of the experimental apparatus.

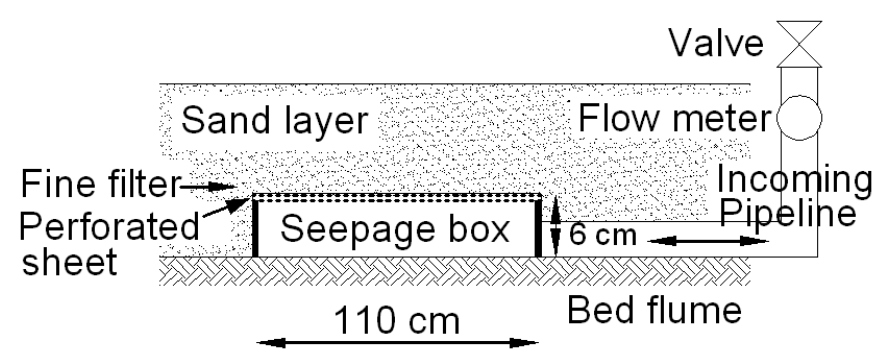

(b) Sketch of the seepage box.

Figure 2: Experimental set-up.

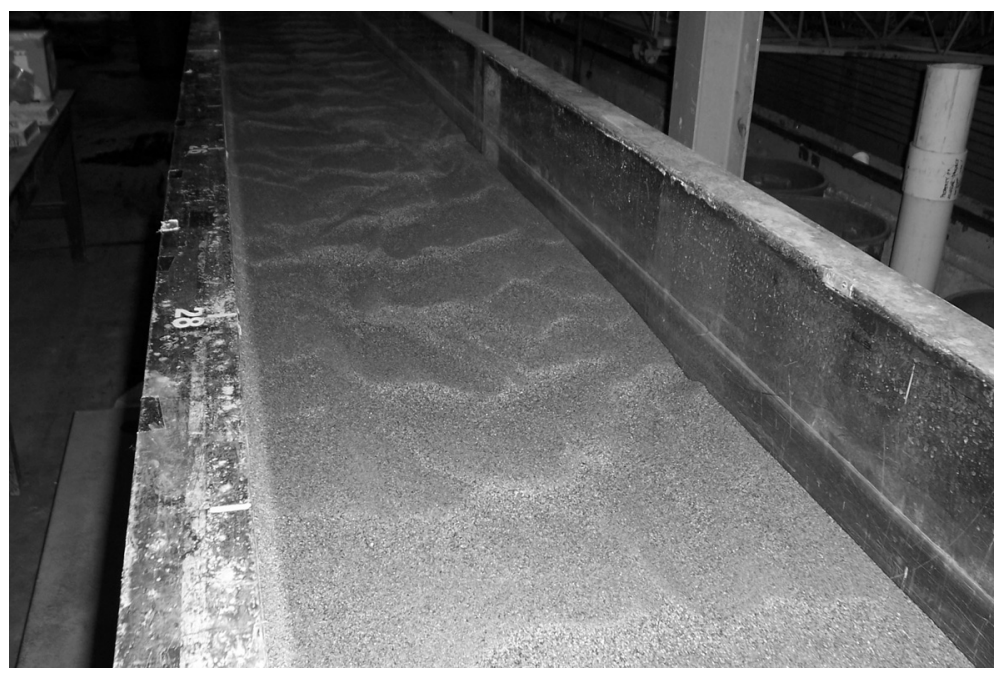

Figure 3: Bedforms at the equilibrium configuration without seepage. 


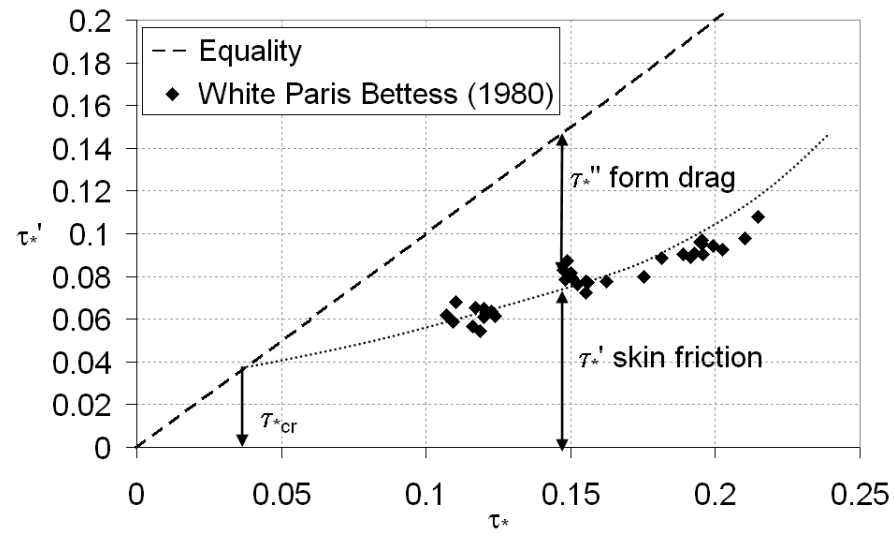

Figure 4: Decomposition of the total dimensionless bed shear stress into a component due to skin friction and a component due to form drag. The data are for the experiments reported here.

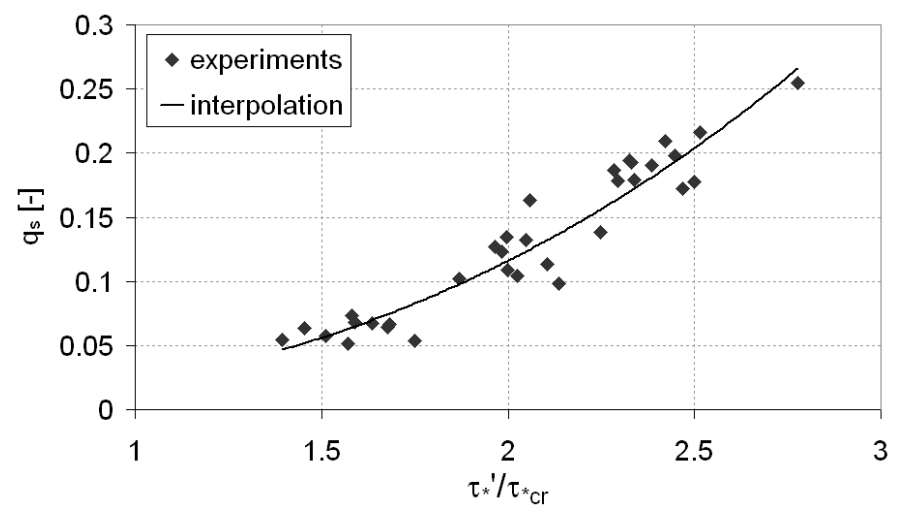

Figure 5: Bedload transport relationship, interpolated from experimental data. 


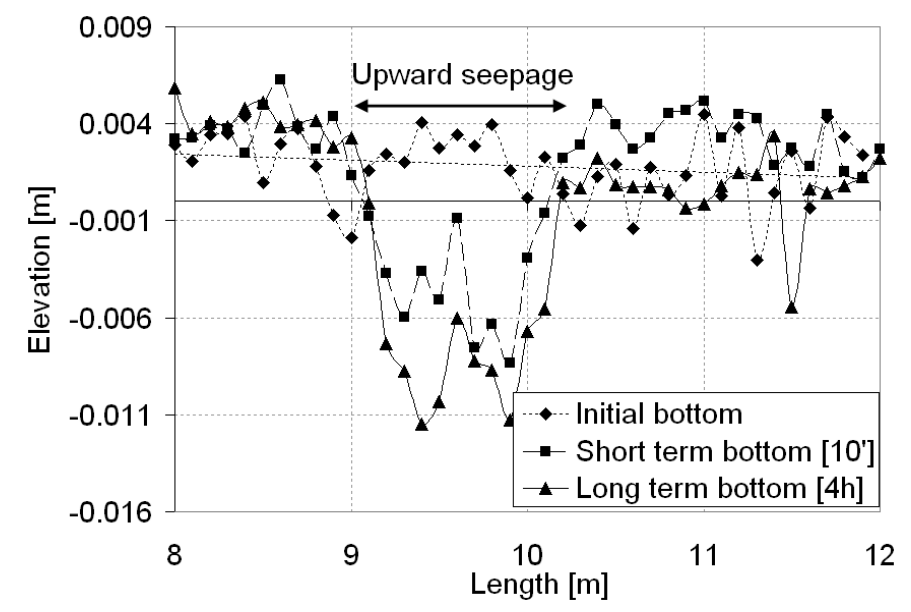

(a) Local scour bed due to upward seepage after the short-term experiment. The effect of average longitudinal slope has been subtracted.

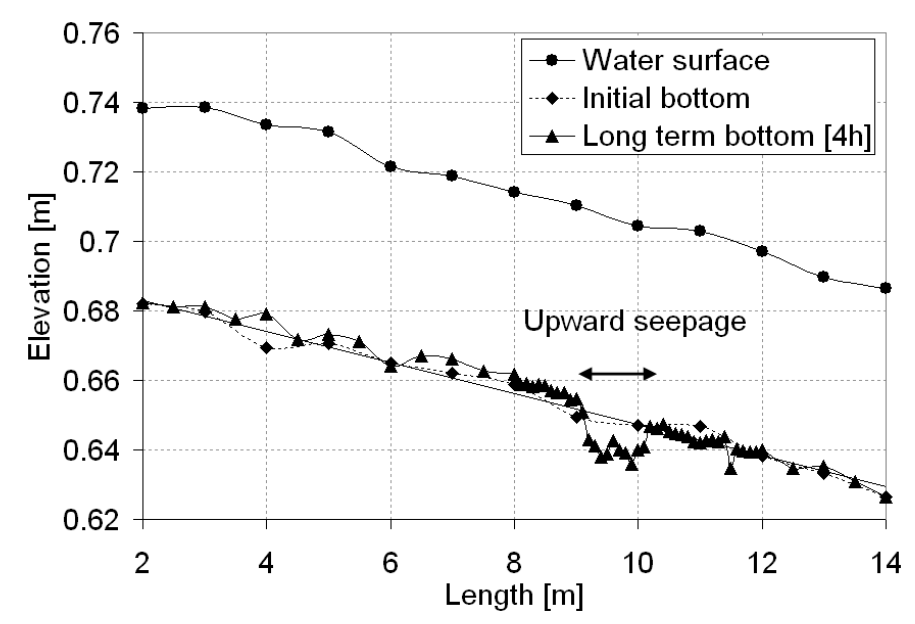

(b) Equilibrium configuration due to upward seepage after the longterm experiment.

Figure 6: Bed elevation profiles in the case of upward seepage (Run 1-2, $Q_{w}=$ $\left.20.6 \mathrm{l} / \mathrm{s}, Q_{\text {seepage }}=40 \mathrm{l} / \mathrm{m}\right)$. 


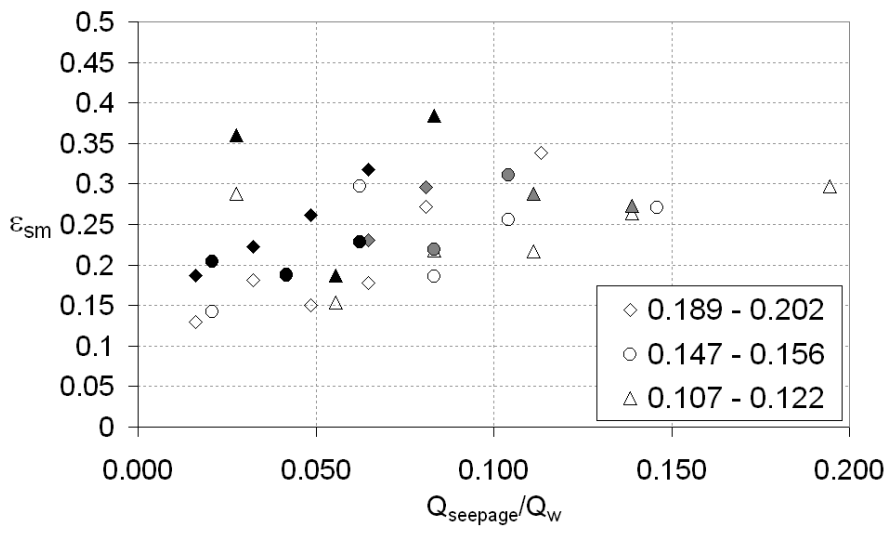

(a) Maximum dimensionless scour depth.

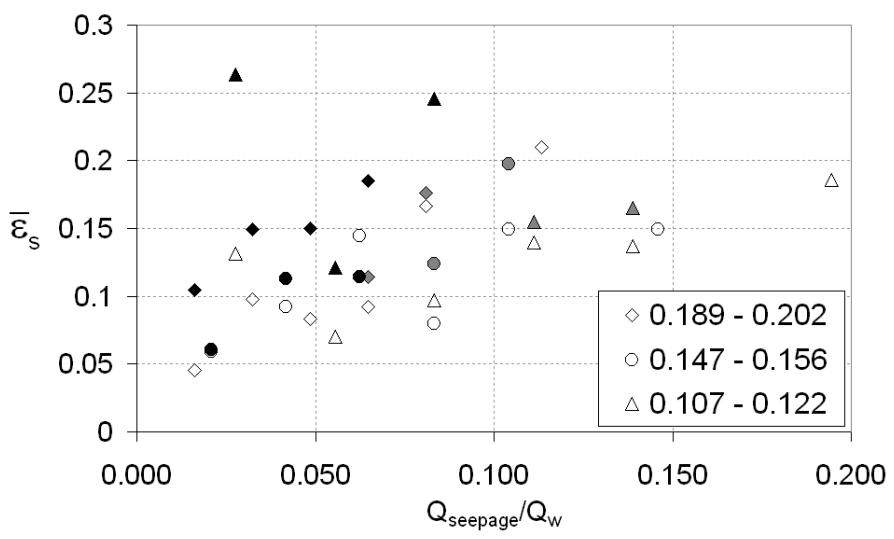

(b) Mean dimensionless scour depth.

Figure 7: Maximum and mean dimensionless scour depth plotted against discharge ratio $Q_{\text {seepage }} / Q_{w}$ for different range of the average Shields parameter in the case of zero seepage at the equilibrium conditions, for the short-term experiments (white dots - 10 minutes) and for the long-term experiments (black dots -4 hours, gray dots -2 hours). 


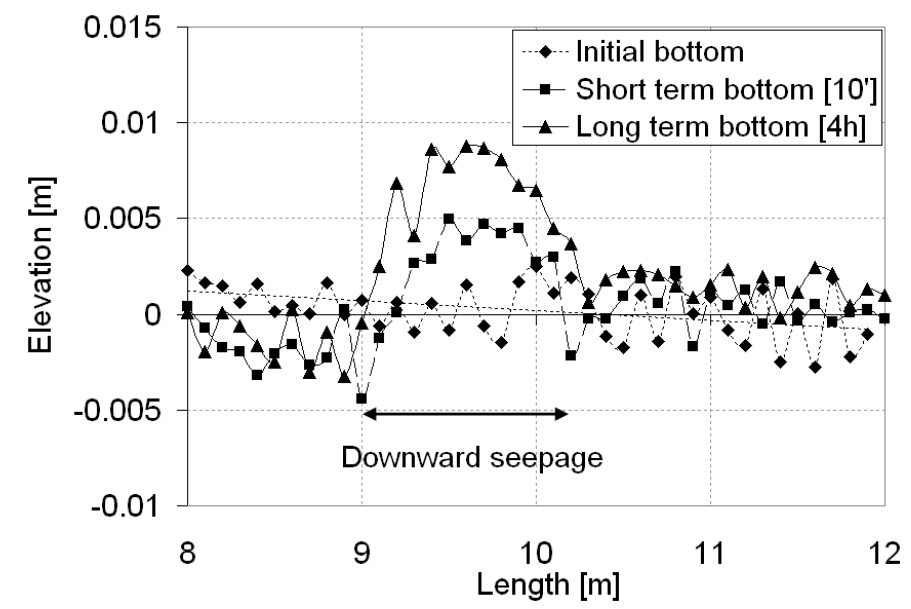

(a) Local scour bed due to downward seepage after the short-term experiment. The effect of average longitudinal slope has been subtracted.

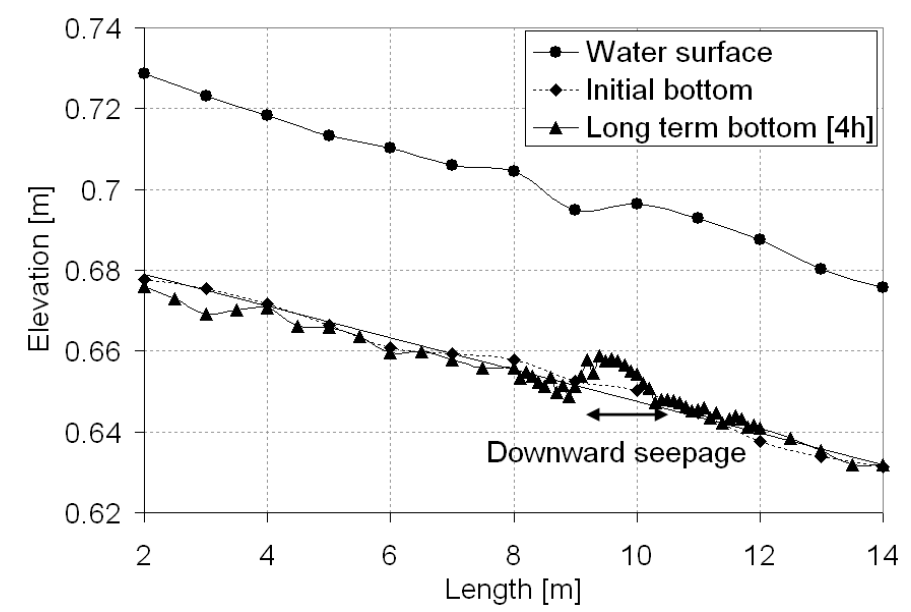

(b) Equilibrium configuration due to downward seepage after the longterm experiment.

Figure 8: Bed elevation profiles in the case of downward seepage (Run 5-2, $Q_{w}$ $\left.=16 \mathrm{l} / \mathrm{s}, Q_{\text {seepage }}=60 \mathrm{l} / \mathrm{m}\right)$. 


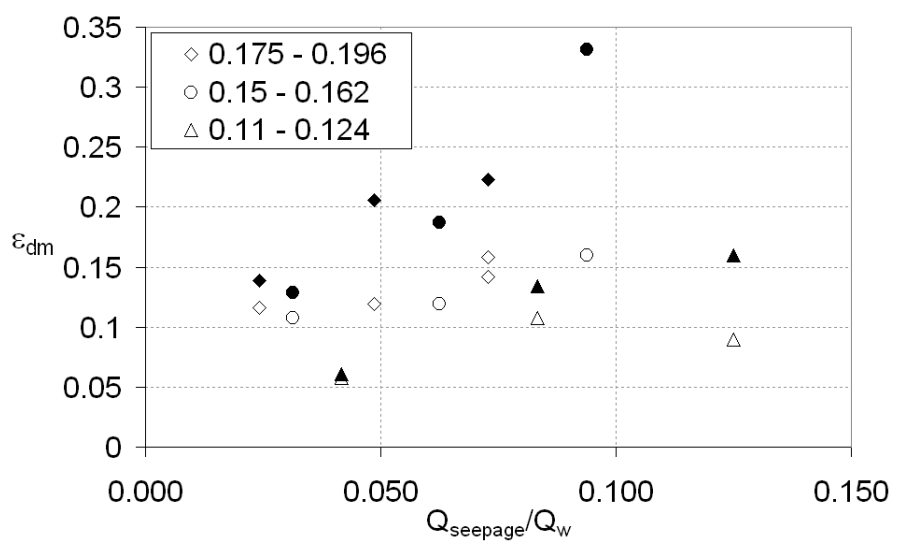

(a) Maximum dimensionless scour deposit.

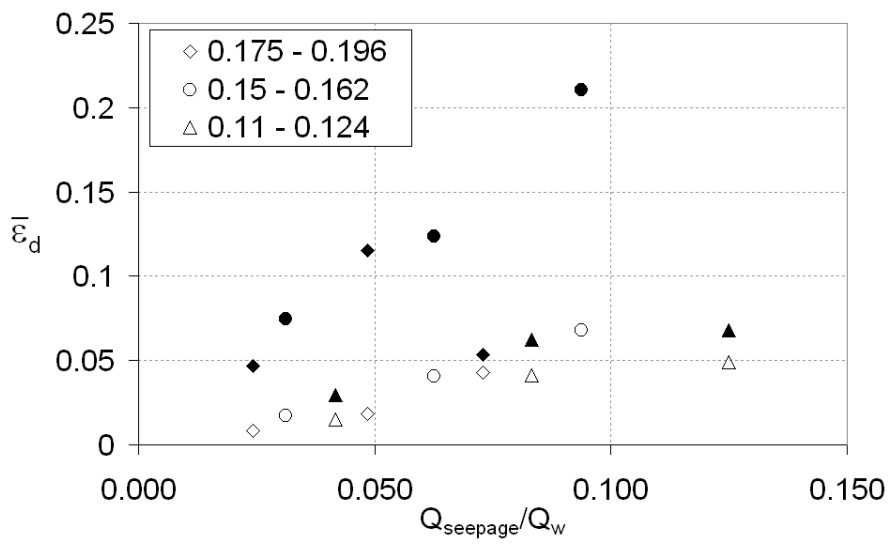

(b) Mean dimensionless scour deposit.

Figure 9: Maximum and mean dimensionless deposit thickness plotted against discharge ratio $Q_{\text {seepage }} / Q_{w}$ for different range of the average Shields parameter in the case of zero seepage at the equilibrium conditions, for the short-term experiments (white dots - 10 minutes) and for the long-term experiments (black dots - 4 hours). 


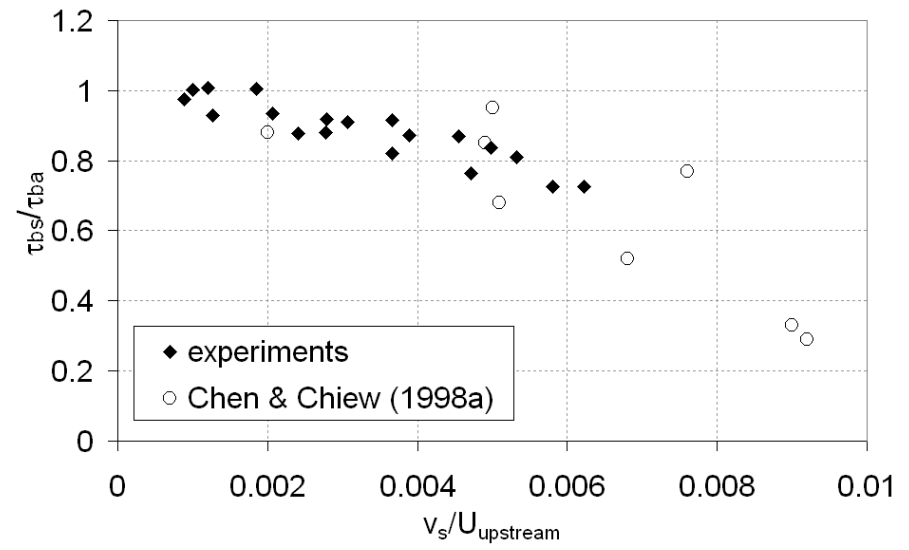

Figure 10: Reduction of the bed shear stress due to upward seepage.

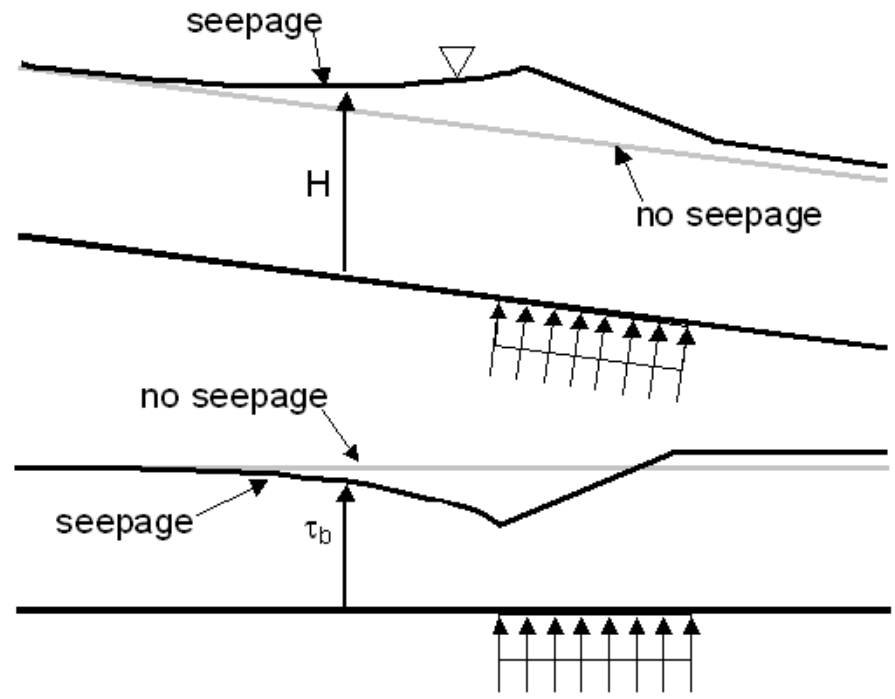

Figure 11: Schematic diagrams showing the patterns of flow depth $\mathrm{H}$ and bed shear stress $\tau_{b}$ induced by a short zone of upward seepage. The profiles pertain to conditions before the bed has evolved in response to the seepage. Note that although the bed shear stress in the middle of the seepage zone is below the value prevailing in the absence of seepage, it is above the values prevailing in the part of the backwater zone immediately upstream of the zone of seepage. 


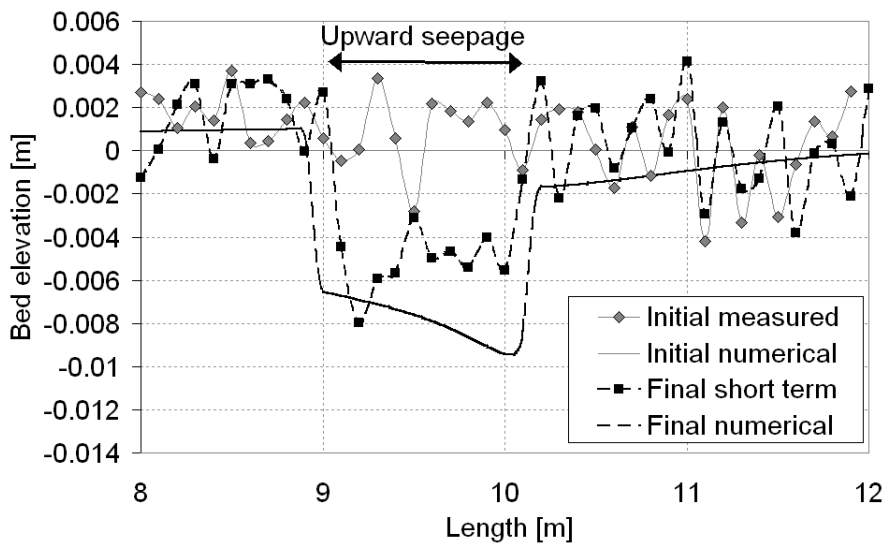

(a) Short-term experiment.

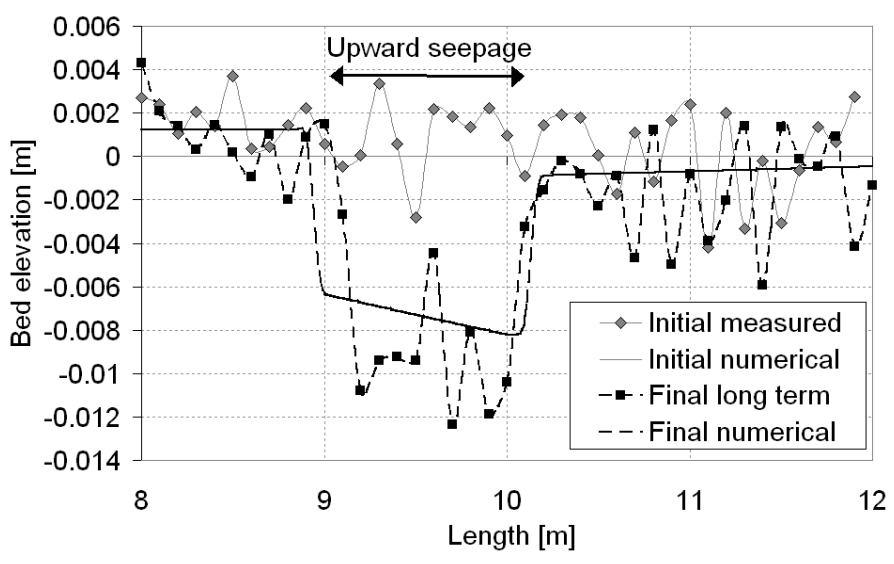

(b) Long-term experiment.

Figure 12: Comparison of experimental and numerical results, Run 1-3. 


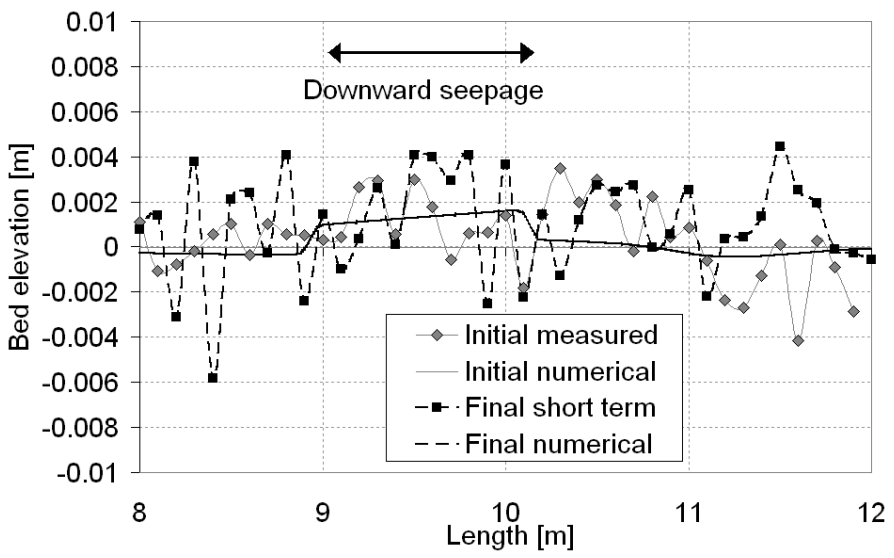

(a) Short-term experiment.

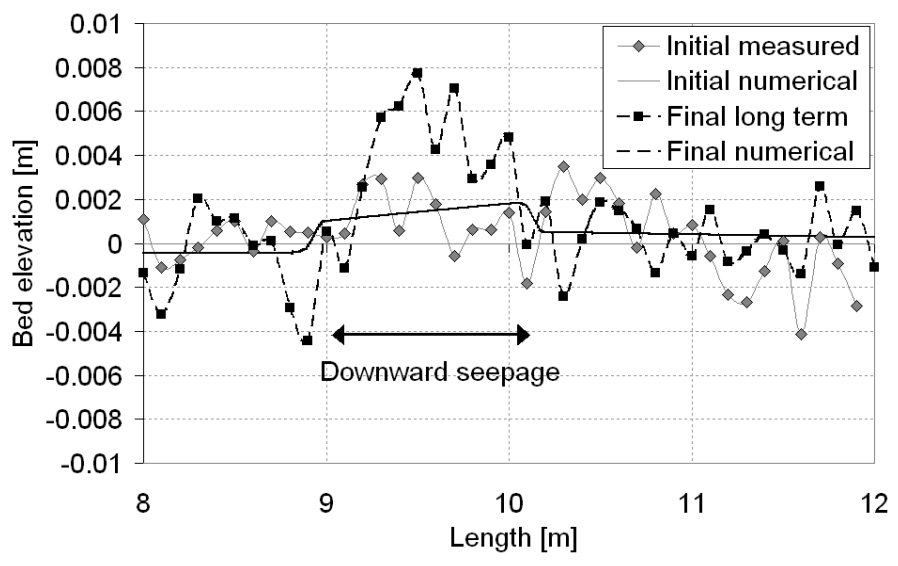

(b) Long-term experiment.

Figure 13: Comparison of experimental and numerical results, Run 4-1. 


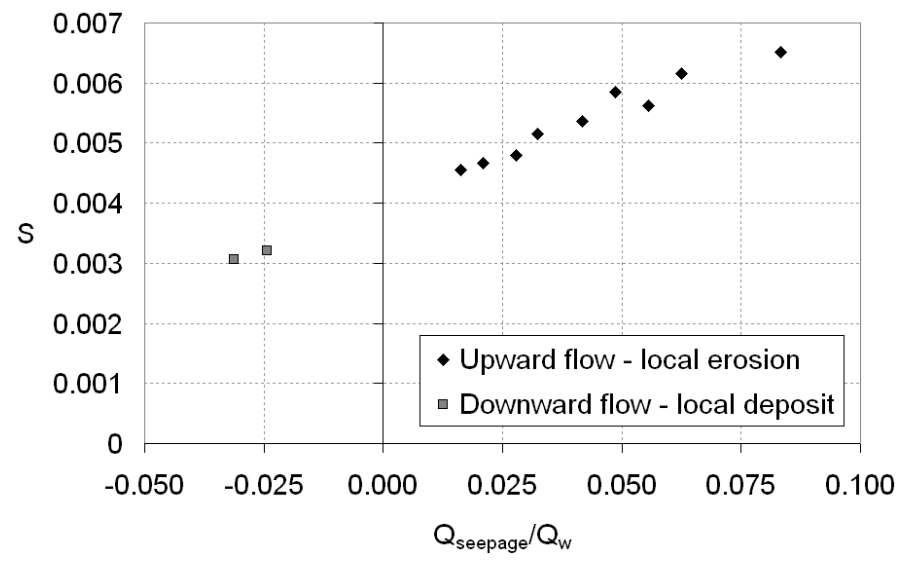

Figure 14: Average local slope, numerically computed, in upward/downward seepage area. 


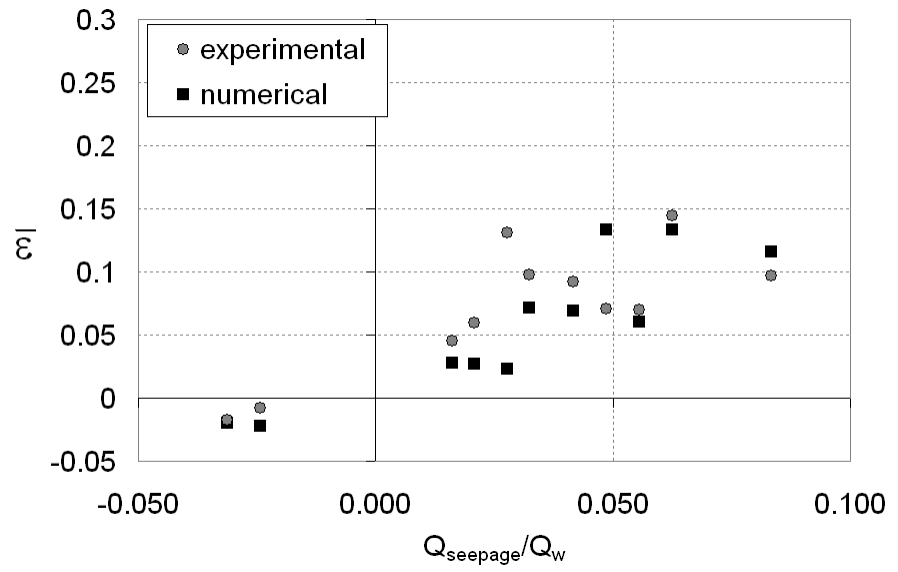

(a) Short-term experiment.

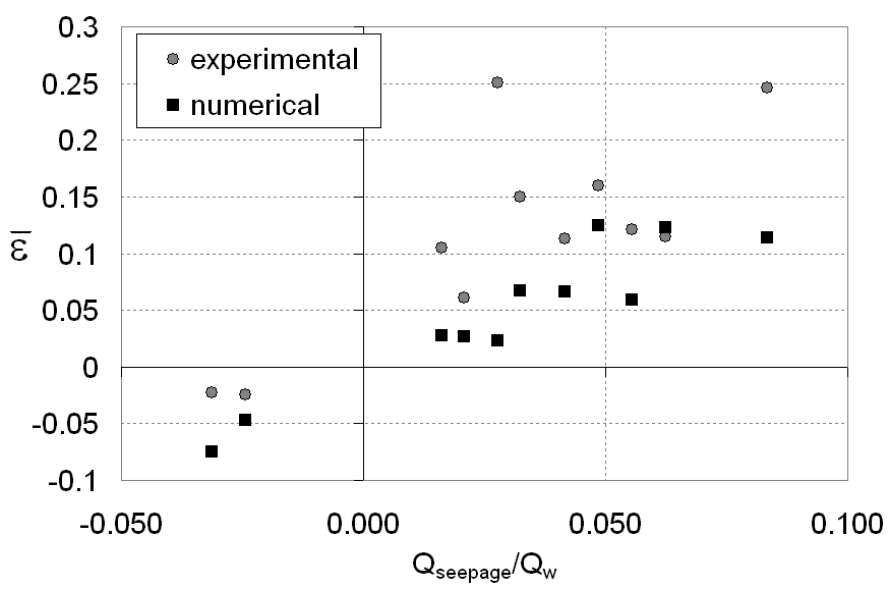

(b) Long-term experiment.

Figure 15: Comparison of experimental and numerical results of the mean scour in the local seepage area. Positive values of mean scour indicate erosion, negative values indicate deposition. 


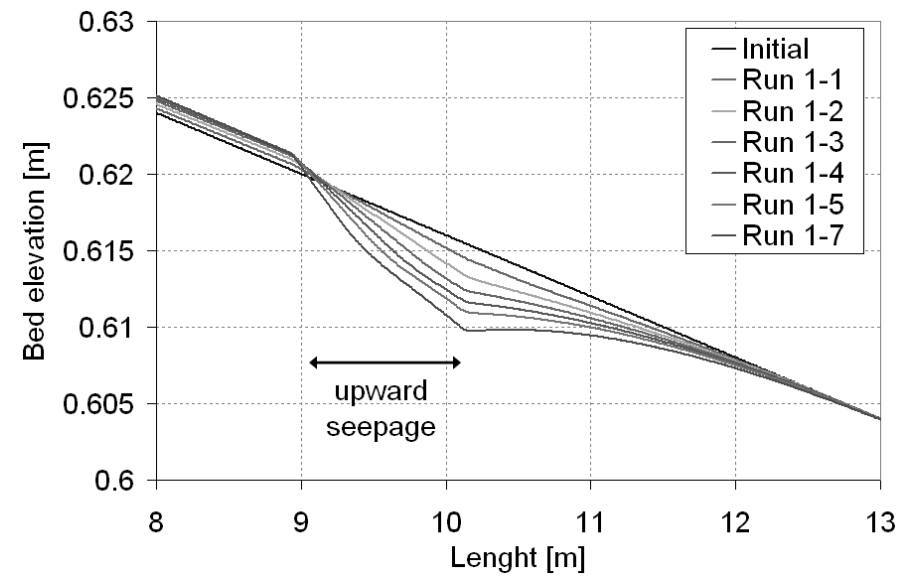

Figure 16: Predictions of the patterns of morphodynamic evolution in cases of upward seepage when the effect of seepage on the bed shear stress is included, but the effects of a non-hydrostatic pressure gradient induced by seepage on bedload transport are neglected. 